\title{
Beyin ölümü tespitinde araş̧ırma hastanesi deneyimi
}

\author{
Muharrem Battal ${ }^{1}$, Aynur Horoz ${ }^{2}$, Oğuzhan Karatepe' ${ }^{1}$ Bülent Çitgez ${ }^{3}$
}

\begin{abstract}
ÖZET:
Beyin ölümü tespitinde araştırma hastanesi deneyimi

Amaç: İstanbul Okmeydanı Eğitim ve Araştırma Hastanesi en çok beyin ölümü tespit edilen merkezlerden biridir. Bu yazıda beyin ölümü tespiti, karşılaşılan sorunlar, travmanın bu konudaki yeri ve ekibimizin bu konudaki tecrübesi paylaşılmaktadır.

Yöntem: Eylül 2007- Ocak 2012 tarihleri arasında Okmeydanı Eğitim ve Araştırma Hastanesi'nde tespit edilen 62 beyin ölümü ve organları nakil merkezlerine dağıtılan 18 kadavranın kayıtları retrospektif olarak incelendi. Hastaların yaş, cins, hastanede yattığı süre, ölüm sebebi, beyin ölümü tespit yöntemi, kan grupları kaydedildi.

Sonuç: Beyin ölümü tanısı 62 hastaya kondu ve 18 aile, (bağışlama oranı \%29) yakınlarının organlarını bağışladı. Beyin ölümü tanısı alan hastaların 45 erkek ve 17 kadındı. Beyin ölümü tespit edilen en küçük yaş 2, en yüksek 84 , ortalama 41 bulundu. Beyin ölümü tespit süresi en erken 16 saat, en uzun süre 600 saat, ortalama 106,2 saatti. Hastaların hepsine apne testi uygulandı. Beyin ölümü olan 36 (\%58) hasta travma ve 26 (\%42) hasta travma dışı nedenler ile takip edilmekteydi. Travmatik subaraknoid kanama en sık tespit edilen problemdi. Travma dışı sebepler spontan subaraknoid kanama ve intraserebral kanamaydı.

Tartışma: Beyin ölümü tanısının konulmasında en önemli etken sağık personelinin konuya yaklaşımıdır. Beyin ölümü tespiti sağlık ekibinin sorumluluğudur. Özellikle kafa travmalı olgularda beyin ölümü gelişebileceği akılda tutulmalıdır. Sağlık ekibi profesyonelce yaklaşmalı, beyin ölümü ve organ bağışı sayısının artması için çaba sarf etmelidir.
\end{abstract}

Anahtar kelimeler: Beyin ölümü, kadavra, apne testi, transplantasyon

\section{ABSTRACT:}

Experience of research hospital in determination of brain death

Objective: Istanbul Okmeydanı Research and Training Hospital is one of the most common health care centers in where declaration of brain death is documented. In this paper, we would like to share our experience about brain death determination, problems, and the role of trauma in this issue.

Method: Between September 2007 and January 2012, 62 brain death and 18 multiorgan donors were detected in Okmeydanı Research and Training Hospital. All patients record were retrospectively reviewed. The patient's age, gender, hospitalization time, the cause of death, brain death detection method and the blood groups were recorded.

Results: Totally 62 brain deaths and 18 organ donors were detected. There were 45 males and 17 womens with a mean age of 41 (range:2-84) years old. The mean time for determination of brain death was 106,2 hours (range: $16-600$ hours). Apnea test was performed in all patients. Trauma cases were found at $36(\% 58)$ patients and non-trauma cases were $26(\% 42)$. Traumatic subarachnoid hemorrhage was the most frequently identified pathogenesis. Other problems were spontaneous subarachnoid hemorrhage and intracerebral hemorrhage.

Discussion: The approach of health care personnel approach is one of the most important factors for brain death determind This is the responsibility of the health care team. In particular, brain death should be kept in in patients with head injury. The medical team should act in professional way and give attention to increase the number of organ donations.

Key words: Brain death, cadaver, apnea test, transplantation

Ş.E.E.A.H. Tıp Bülteni 2013;47(2):59-62
'Okmeydanı Eğitim ve Araştırma Hastanesi, Genel Cerrahi Servisi, i̇stanbul-Türkiye ${ }^{2}$ Okmeydanı Eğitim ve Araştırma Hastanesi, Organ Nakil Koordinatörü, i̇stanbul-Türkiye ${ }^{3}$ Şişli Etfal Eğitim ve Araştırma Hastanesi Genel Cerrahi Servisi, i̇stanbul-Türkiye

Yazışma Adresi / Address reprint requests to: Muharrem Battal, Okmeydanı Eğitim ve Araştırma Hastanesi, 2. Genel Cerrahi Kliniği, Şişli, İstanbul -Türkiye

Telefon / Phone: +90-212-221-7777

E-posta / E-mail:

muhbattal@yahoo.com

Geliş tarihi / Date of receipt: 15 Ocak 2012 / January 15, 2012

Kabul tarihi / Date of acceptance: 10 Temmuz 2012 / July 10, 2012 


\section{Giriș}

Son 20 yılda transplantasyon alanındaki gelişmeler baş döndürücüdür. Daha önce hayal olarak değerlendirilen birçok işlem artık rutin prosedürler haline gelmiştir. Böbrek, karaciğer, kalp, kornea gibi rutin uygulanan nakillerin yanında son yıllarda akciğer, pankreas, ince barsak yanında ekstremite ve yüz nakli uygulanmaya başlamıştır. Ülkemizde organ nakli ile ilgili gelişmeler 2000 yılından sonra hız kazanmış, Sağlık Bakanlı̆̆ı'nın desteği ile önemli gelişmeler sağlanmıştır.

Beyin ölümü, tüm beyin fonksiyonlarının geri dönüşsüz kaybıdır. Beyin ölümü kavramı ilk defa 1959 da tanımlanmıştır. 1968 yılında Harvard Kriterleri oluşturularak beyin ölümü tanısı standardize edilmiştir (1). Son 20 yolda organ naklindeki gelişmeler sonucunda yeterli organ bulunamaması nedeniyle beyin ölümü ve organ bağışı daha önemli hale gelmiştir.

Organ temini için 2 yol vardır; Canlı vericiler yoluyla veya kadavradan organ temini. Günümüzde canlı vericilerden organ temini güvenle uygulanabilen bir işlem olmasına karşın tamamen sağlıklı bir kişinin riske edilmesi kaçınılmazdır. Yeterli kadavra bulunamaması nedeniyle canlıdan organ temini arayışı vardır. Kadavradan organ temini en güvenli kaynaktır. Aynı zamanda kalp, pankreas, akciğer, ince barsak ve kornea sadece kadavradan elde edilebilen organlardır. Bu nedenle kadavradan organ sayısının arttırılması gerekmektedir. Avrupa'da ortalama 20-30/milyon kişi olan kadavra organ bağışı, ülkemizde 3/milyon kişidir. Bir araştırmada ideal oranın 50 Adet/milyon olduğu bildirilmiştir (2).

Kadavra organ temininde en önemli merkezler bünyesinde yoğun bakım üniteleri bulunan travma merkezleridir. Özellikle izole kafa travması ve multipl travmalı olgularda en ciddi durum beyin ölümünün gerçekleşmesidir. Sağlık ekibi her an böyle bir durumla karşılaşabileceğini, beyin ölümü tespiti için neler yapması gerektiğini bilmelidir.

Türkiye de bu konu sağlık bakanlığının 01.06.2000 tarih ve 24066 sayılı kanun ile yönetilmektedir. Beyin ölümü tespiti yine sağlık bakanlığının 05/03/2010 tarih ve 27512 sayılı yönetmeliğinde tarif edildiği gibi belirlenmektedir (3). Bu çalışmadaki amacımız beyin ölümü tespiti, karşılaşılan sorunlar, travmanın bu konudaki yeri ve ekibimizin bu konudaki tecrübesi paylaşılmaktadır.

\section{GEREÇ ve YÖNTEM}

Eylül 2007- Ocak 2012 tarihleri arasında Okmeydanı Eğitim ve Araştırma Hastanesi'nde tespit edilen 62 beyin ölümü ve bu olgular arasında organları nakil merkezlerine dağıtılan 18 kadavranın kayıtları retrospektif olarak incelendi. Hastaların yaş, cins, hastanede yattığı süre, ölüm sebebi, kan grupları tespit edildi.

\section{SONUÇLAR}

Toplam 62 hastaya beyin ölümü tanısı kondu ve 18 (bağışlama oranı \%29) olguda organ bağışı oldu. Beyin ölümü tanısı konanların 45 erkek ve 17 kadın ve organlarını bağışlayanların 15 erkek, 3 kadındı. Beyin ölümü tespit edilen en küçük yaş 2 , en yüksek 84, ortalama 41 idi. Beyin ölümü tespit süresi en erken 16 saat, en uzun süre 600 saat, ortalama 106,2 saatti. Ancak uzun süre yoğun bakımda takip edilen 3 hasta çıkarıldı ̆̆ında bu süre 85 saat olarak tespit edildi. Hastaların hepsine apne testi uygulandı. 2 hasta beyin ölümü tespit edildikten sonra aile onayı beklerken kaybedildi.

Otuzaltı hasta travma nedeniyle ve 26 hasta travma dışı sebepler ile beyin ölümü gelişti. Travmanın beyin ölümü tespit edilen hastalar arasındaki oranı \%58 idi.Travma hastalarında, travmatik subaraknoid kanama en sık tespit edilen problemdi. Travma dışı sebepler spontan subaraknoid kanama ve intraserebral kanamaydı. Kan grupları dağılımı; A kan grubu, 33 hasta toplam; B kan grubu: 7 hasta; O kan grubu 19 hasta $A B$ kan grubu: 3 hasta şeklinde idi.

\section{TARTIŞMA}

Organ nakli konusunda insanların bilinçlendirilmesi en önemli konudur. Sağlıklı bir kişinin günün birinde organa ihtiyaç duyabileceğini anlaması çok zordur. İnsanlar sadece ihtiyacı olduğunda konunun önemini kavramaktadırlar. Bu nedenle konunun insanların insiyatifine bırakmak yerine açık, anlaşılır, 
uygulanabilir, kurallar ile ele alınması gereklidir(4).

Bu konuda sağlık personelinin tavrı çok önemlidir. Özellikle en çok beyin ölümü tespit edilen yoğun bakım üniteleri, beyin cerrahi ve nöroloji klinikleri ile acilde görevli olan travma doktorlarının bu konudaki tavırları belirleyicidir. Böylesine ciddi bir durumda beyin ölümü gerçekleşen hastanın ailesinin kararını etkileyecek en önemli faktör hastadan primer sorumlu olan sağlık ekibinin tavrı, inandırıcılığı ve verdiği güven duygusudur. Kendisi şüphe içinde olan bir ekibin kadavra donor için aile onayı alamayacağı açıktır. Tüm dünyada aile onayı \%30-40 oranındadır (5). Beyin ölümü adayı olan hastaların tamamı herhangi bir nedenle yoğun bakım ünitelerinde, entübe olarak takip edilen hastalardan oluşmaktadır. Bu hastalar, yoğun bakım ilkeleri ile takip edilmektedirler. Hastaların çoğu reanimatörler tarafından ve diğer problemleri nedeniyle beyin cerrahi uzmanları veya nöroloji doktorları tarafından da takip edilmektedirler. Bu ekipler her hastayı Glasgow koma skalası (GKS) ile değerlendirmektedirler. GKS 7'nin altında olan her hastada beyin ölümü gelişebileceği düşünülmeli ve bu açıdan takibe alınmalıdır.

Ülkemizde kanunen beyin ölümü tespit komisyonunda 4 uzman bulunmaktadır. Bunlar beyin cerrahi uzmanı, nöroloji uzmanı, kardiyoloji ve anestezi uzmanıdır. Kanunen her hastaya apne testi uygulanması zorunludur ve bu test anestezi uzmanı tarafından uygulanır. Reanimasyon servisinde takip edilen hastalar beyin ölümü değerlendirmesi için en az 24 saat önceden sedasyon almadığından emin olunmalıdır (6).

Beyin ölümü tespit edildikten sonra tanının doğrulanması için yardımcı yöntemler gerekli olabilmektedir. Beyin ölümü tanısında yardımcı olarak intrakranial Doppler ultrasonografi, bilgisayarlı tomografimanyetik rezonans anjiografi, beyin sintigrafisi, elektroensefalografi uygulanabilir $(7,8)$. Beyin ölümü tespit edildikten sonra birçok ülkede çoğunlukla 6-24 saat arasında değişen bekleme periyodu uygulanmaktadır. Ülkemizde bu şekilde bir bekleme süresi yoktur (9).

Okmeydanı Eğitim ve Araştırma Hastanesi'nde ilk defa Eylül 2007'de beyin ölümü tespit edilmiştir. Hastanemizde bu konuda organ nakil koordinatörü olarak bir sağlık personeli görevlendirilmiş. Bu konu- da kendisine yardımcı olmak üzere transplantasyon konusunda gönüllü bir genel cerrahi uzmanı görevlendirilmiştir. İlk olgularda sağlık personelinin beyin ölümü tespitine sıcak yaklaşmadığı bir gerçektir. Bunun nedeni meslektaşlarımızın konuyu bilmemeleri, sorumluluk almaktan kaçınmaları ve fazladan işgücü gerektiğini düşünmeleri olarak sıralanabilir. Bu konularda ilk görüşülen kişi hastane organ nakil koordinatörüdür. Bu personelin sorunları çözemediği noktada görevli hekimin devreye girmesi ile çoğu mesele halledilebilmektedir. Bu yolla, organ nakil koordinatörüne yardımcı olunmakta, aynı zamanda diğer sağlık personeli üzerinde de bilgilendirme, otorite ve güven duygusu oluşturulmaktadır. Bu konu üzerinde durulmasının sonucu olarak yaklaşık 4 yılda 62 beyin ölümü tespit edilmiş ve 18 organ bağışı sağlanmıştır.

Olgularımız incelendiğinde çoğunluğunun tüm dünyada olduğu gibi travma hastası olduğu görülecektir (10). Özellikle beyin cerrahi kliniklerinin olduğu travma merkezlerinde bu konuya daha ciddi yaklaşılmalıdır. Hastaların çoğunda beyin ölümü tanısı ilk 72 saatte yani ortalama 3 günde konabilmektedir. Hastaneye başvuran hastaların durumlarının ciddiyetine göre beyin ölümü gelişebileceği akılda tutulmalı ve bu açıdan da takip edilmesi gerekmektedir. Beyin

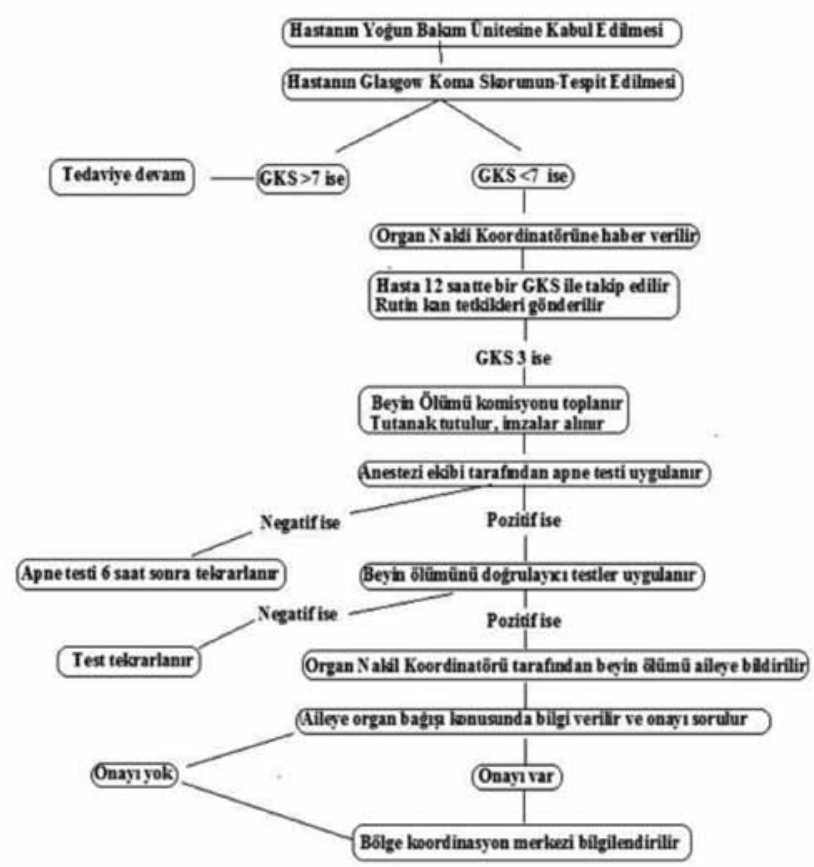

Şekil 1: Beyin ölümü tespit şeması 
ölümü tespitinde hastanemizde uygulanan protokol Şekil 1'de gösterilmektedir.

Beyin ölümü tespit edilen ve aile onayı alınan olgular bölge organ koordinasyon merkezine bildirilmektedir. Bu merkez hasta hakkında kan grubu, hepatit markerları, karaciğer ve böbrek fonksiyon testleri, uzun süre yoğun bakımda takip edilenler için kan kültürü, kalp nakli için verici olabilecek adaylar için ekokardiyografi gibi testler gerekli olabilmektedir. Bu nedenle beyin ölümü riski olan kişilerde (GKS 7 'nin altında olanlar), bu testler organ nakil koordinatörünün rehberliğinde yaptırılmalıdır.

Beyin ölümü tespit edilen olgularda hastaların genel durumları hızla bozulmaktadır. İki olgumuzda beyin ölümü tespit edilmesine rağmen, aile görüşmesi sırasında kaybedilmişlerdir. Bu nedenle çabuk davranılmalı, gereksiz zaman kaybından kaçınılmalıdır. Daha önceden gerekli tetkiklerin hazırlanması zaman kaybını azaltacaktır.

Sonuç olarak sadece sağlık personelinin bilinçlendirilmesi yeterli olmamaktadır. Bu konuda sağlık bakanlığı, sağlık müdürlükleri ve hastane yönetimlerinin gerekli otoriteyi göstermeleri önemlidir. Bir kılavuz yol olmaması konuyu kişilere bağımlı hale getirmektedir. Beyin ölümü tespiti sağlık ekibinin sorumluluğudur. Sağlık ekibi bu konuda profesyonelce yaklaşmalı, beyin ölümü ve organ bağışı sayısının artması için çaba sarfetmelidir.

\section{KAYNAKLAR}

1. Farrell MM. Levin DL. Brain death in the pediatric patient: historical, sociologicali medicali religiousi culturali legal and ethical considerations. Crit Care Med 1993; 21(12): 1951-65.

2. Lien B. Brekke IB. How to improve the rate of organ donation for transplantation? Tidsskr Nor Laegeforen 1999;119(24): 3610-4.

3. Organ ve doku nakli hizmetleri yönetmeliği, Türkiye Cumhuriyeti, Resmi Gazete Tarihi: 01.06.2000 Resmi Gazete Sayısı: 24066.

4. Anker $A E$, Feeley TH, Friedman E, Kruegler J.Teaching organ and tissue donation in medical and nursing education: a needs assessment. Prog Transplant. 2009;19(4):343-8.

5. Jansen $N E$, van Leiden HA, Haase-Kromwijk BJ, Hoitsma AJ. Organ donation performance in the Netherlands 2005-08; medical record review in 64 hospitals. Nephrol Dial Transplant. 2010; 25(6):1992-7.
6. Nakagawa TA, Ashwal S, Mathur M, Mysore M. Clinical Report-Guidelines for the Determination of Brain Death in Infants and Children: An Update of the 1987 Task Force Recommendations. Pediatrics. 2011;128 (3):720-40.

7. Wijdicks EF, Varelas PN, Gronseth GS, et al. Evidence-based guideline update: determining brain death in adults: report of the Quality Standards Subcommittee of the American Academy of Neurology. Neurology 2010; 74: 1911.

8. Facco $E$, Munari M, Gallo F, et al. Role of short latency evoked potentials in the diagnosis of brain death. Clin Neurophysiol 2002; 113:1855.

9. Rossetti AO, Oddo M, Logroscino G, Kaplan PW. Prognostication after cardiac arrest and hypothermia: a prospective study. Ann Neurol 2010; 67: 301.

10. Goudreau JL, Wijdicks EF, Emery SF. Complications during apnea testing in the determination of brain death: predisposing factors. Neurology 2000; 55: 1045. 